\title{
El poder escrito: problemáticas y significación de las inscripciones árabes de los palacios de Pedro I de Castilla (1350-1369)
}

\author{
Julie MARQUER \\ Universidad Paris-Sorbonne \\ CLEA (EA 4083) \\ juliemarquer@yahoo.fr
}

\section{RESUMEN}

El recurso a las inscripciones árabes por parte de Pedro I se incluye en un proyecto arquitectónico más amplio que se inspira directamente en los modelos andalusíes -como lo han demostrado Antonio Almagro Gorbea y Juan Carlos Ruiz Souza- y plantea una serie de interrogantes. En efecto, la asimilación de códigos islámicos representativos del poder por parte de un rey cristiano nos insta a reflexionar sobre el sentido y la función de estas inscripciones ya que la epigrafía está estrechamente vinculada con el islam y el mensaje coránico. Además, se plantea el problema de la recepción de una lengua diferente de la que suelen emplear el comandatario de las inscripciones y su entorno. Intentaremos mostrar cómo estas inscripciones árabes pueden servir al objetivo de fortalecer el poder regio en Castilla en el ámbito simbólico, desde varias perspectivas: por el efecto general que intentan producir en el destinatario, por el contenido ideológico del discurso epigráfico y por la propia actividad discursiva es decir por el mero hecho de recurrir a la epigrafía árabe.

Palabras clave: Pedro I de Castilla, epigrafía árabe, poder, propaganda, legitimación, Alcázar de Sevi1la, Islam, Granada, Al-Andalus, transferencia cultural.

\section{The written power: problems and meaning of the Arabic inscriptions in the palaces of Pedro I of Castile (1350-1369)}

\begin{abstract}
Peter I's use of Arabic inscriptions lies within the scope of a wider architectonic project which draws its inspiration straight from patterns inherited from al-Andalus -as shown by Antonio Almagro Gorbea y Juan Carlos Ruiz Souza- and raises a series of questions. Indeed, the assimilation by a Christian king of Islamic codes representative of power leads us to think about the meaning and the function of these inscriptions since epigraphy is closely related to Islam and the Koranic message. Moreover, it raises the problem of the reception of a language different from that which is commonly used by the originator of the inscriptions and his environment. We will try to show, from various angles, how the symbolical value of these Arabic inscriptions can serve the king's attempts of reinforcing his political power in Castile: through the general effect they are intended to produce on the reader, through the ideological content of the epigraphic discourse and through the discursive act itself, i.e. the mere fact of resorting to Arabic epigraphy.
\end{abstract}

Key words: Peter I of Castile, Arabic epigraphy, power, propaganda, legitimacy-building, Alcázar of Seville, Islam, Granada, Al-Andalus, cultural transfer. 
La escritura "emblemática" árabe está vinculada al palacio ya que adorna una parte importante de las paredes y forma parte de un programa arquitectónico más amplio que desempeña un papel importante en la representación simbólica del poder. Como lo han demostrado varios epigrafistas ${ }^{1}$ especialmente para el ámbito musulmán, estas inscripciones constituyen un instrumento de poder en la medida en que transmiten cierta visión de la realeza, exponen la manera en la que el monarca quiere ser percibido, e intentan también impactar al visitante. Ya que estas inscripciones son un instrumento de propaganda, el tema de su recepción por parte del espectador parece central.

Ahora bien, el uso de las inscripciones árabes en el palacio de un rey castellano y cristiano como Pedro I de Castilla plantea una serie de interrrogantes. Ya que la escritura árabe está estrechamente vinculada al islam y al mensaje coránico, entonces ¿qué impacto y qué sentido pueden tener estas inscripciones en un entorno diferente en cuanto a la lengua y a la religión? ¿Equivale este préstamo a una mera copia desprovista de una parte de su sentido? ¿Cómo la transferencia del objeto epigráfico a otro entorno puede servir al rey castellano?

La función propagandística de estas inscripciones ha provocado un interesante debate. Primero porque varios historiadores opinan que Pedro I no entendía estas inscripciones, o que no estaban destinadas a ser leídas o que poca gente tenía acceso a ellas. En este caso, se plantearía el problema de la intención y también de la recepción ya que la razón de ser de la propaganda es transmitir un mensaje para convencer a un receptor de que adhiera a la causa defendida por el emisor de la propaganda.

Pedro I no fue el primer monarca cristiano en recurrir a la epigrafía árabe en sus construcciones: desde el siglo XII eulogías, frases doxológicas o fórmulas propiciatorias en árabe aparecen en los edificios cristianos ${ }^{2}$. Además de presentarse como la consecuencia de una permeabilidad cultural, favorecida por el contacto prolongado entre grupos confesionales, la presencia de las inscripciones árabes en los palacios de Pedro I es el resultado de un contexto político peculiar. La relación de poder claramente establecida con Granada y la proximidad de los dos monarcas favorecen la permeabilidad de la frontera y la emulación artística. Además, el conflicto que caracteriza el reinado de Pedro I en constante lucha contra Aragón y contra su hermanastro Enrique de Trastámara, que cuestiona su legitimidad, puede explicar que Pedro I recurra a un aparato propagandístico capaz de hacer el elogio de la figura del rey. Como bien han indicado Antonio Almagro y Juan Carlos Ruiz Souza, Pedro I desarrolla un programa arquitectónico sin precedentes en el ámbito cristiano ${ }^{3}$. Las inscripciones se insertan así

1 M.A. MARTÍNEZ NÚÑEZ, "Escritura árabe ornamental y epigrafía andalusí”, Arqueología y Territorio medieval, 4 (1997), pp. 127-162 y "Epigrafía y propaganda almohades", Al Qantara, 18 (1997), pp. 415- 445; y P. CANO ÁVILA y A.T. MOHAMED ESSAWI, "Estudio epigráfico-histórico de las inscripciones árabes de las ventanas y portalones del Patio de las Doncellas del Palacio de Pedro I en el Real Alcázar de Sevilla”, Apuntes del Alcázar, 5 (2004), pp. 59-79.

2 B. PAVÓN MALDONADO, Tratado de arquitectura hispano-musulmana 3, Palacios, Madrid, 2004, p. 872; y J. MARQUER, "Epigrafía y poder: el uso de las inscripciones árabes en el proyecto propagandístico de Pedro I de Castilla (1350-1369)", e-Spania [En línea], 13 juin 2012, http://e-spania.revues.org/21058.

3 A. ALMAGRO GORBEA, Antonio, "La recuperación del jardín medieval del Patio de las Doncellas", Apuntes del Alcázar de Sevilla, 6 (2005), pp. 44-67 y Palacios medievales hispanos, Real Academia de Bellas Artes de San Fernando, 2008; J.C. RUIZ SOUZA, Estudios y reflexiones sobre la arquitectura de la Corona de Castilla y Reino de Granada en el siglo XIV: creatividad y/o crisis, tesis doctoral (U.A.M), Madrid, 2000 
en este proyecto arquitectónico destinado a enfatizar la figura del soberano, intimidar al visitante y convencerle de que es un espacio sagrado mediante diversos procedimientos que retoman la simbólica islámica del poder.

Intentaremos mostrar aquí cómo estas inscripciones árabes pueden servir o reflejar la empresa de fortalecimiento del poder regio en Castilla en el ámbito simbólico, desde varias perspectivas ${ }^{4}$. Primero es necesario interesarse por el efecto general que intentan producir en el destinatario, luego por el contenido ideológico del discurso epigráfico más difícil de descifrar pero que informa sobre la concepción del poder del soberano. Por fin, la propia actividad discursiva es decir el mero hecho de recurrir a la escritura árabe, también desempeña un papel importante en la representación del poder regio.

En cuanto al corpus de estas inscripciones, nos apoyaremos en parte en los trabajos de José Amador de los Ríos ${ }^{5}$ y sobre todo en las inscripciones que han sido revisadas por Pedro Cano en su artículo publicado en la revista Apuntes del Alcázar ${ }^{6}$.

\section{Impactar al visitante: el discurso hecho signo}

Se tiende a pensar que en los palacios castellanos, las inscripciones árabes pierden una gran parte de su objetivo propagandístico por la dificultad de comprensión que supone el uso del árabe. En aquella época, excepto quizás los sultanes o embajadores musulmanes ${ }^{7}$ que pasaron por la corte de Pedro I, poca gente era capaz de descifrarlas. ¿Tenemos que considerar por lo tanto que se reducían a un simple adorno vacío de significado?

En cuanto a los posibles destinatarios arabófonos, si bien podían leer las inscripciones en estilo nasjí, la comprensión de las cúficas podían resultar más complicadas de entender. En efecto, al tratar sobre todo del cúfico, el gran epigrafista Manuel Ocaña Jiménez ya mostró que a los gobernantes musulmanes no les importaba que las inscripciones no fuesen entendidas por la mayoría de los súbditos. El carácter suntuoso de los edificios valía más que las frases de elogio a Dios para atraer el respeto del pueblo. Según Ocaña, las inscripciones en cúfico "constituían una incógnita para la mayoría de los musulmanes", incluso para los artesanos que "trabajaban de pura rutina".

A pesar de que las problemáticas de las inscripciones latinas no sean exactamente las mismas que las inscripciones árabes, podemos valernos de una prudente comparación

y "Castilla y Al-Andalus. Arquitecturas aljamiadas y otros grados de asimilación”, Anuario del Departamento de Historia y Teoría del Arte, (UAM), 16 (2004), pp. 17-43.

4 A propósito de las inscripciones árabes de los palacios de los reyes normandos en Sicilia, Annliese Nef distingue dos niveles de análisis : el efecto general buscado y el detalle de la realización artística que se articula de manera coherente para expresar concepciones precisas, A. NEF, Conquérir et gouverner la Sicile islamique aux XI et XII siècles, Roma, 2011, pp. 157-158.

5 R. AMADOR DE LOS RÍOS, Inscripciones Árabes de Sevilla, Sevilla,1998.

6 P. CANO ÁVILA, op. cit, 2004.

7 Pedro I acogió a varios sultanes granadinos y meriníes en su corte, R. ARIÉ, "Les relations entre le royaume nasride de Grenade et le Maghreb de 1340 à 1391", M. GARCÍA ARENAL y M.J. VIGUERA (eds.), Relaciones de la Peninsula Ibérica con el Magreb (siglos XIII-XIV), Madrid, 1988, pp. 21-40. Pedro I también recibió a varios embajadores musulmanes como Ibn Khaldun, J.P. MOLÉNAT, "Ibn Jaldún ante Pedro I de Castilla, el revés de un encuentro", El Mediterráneo en el siglo XIV, Auge y declive de los Imperios, Granada, 2006, pp. 164-169.

8 M. OCAÑA JIMÉNEZ, El cúfico hispano y su evolución, Madrid, 1970, pp. 11-13. 
para entender mejor el efecto que podían producir estas inscripciones en el público receptor. A propósito de las inscripciones latinas, la epigrafista Cécile Treffort muestra que la razón de la inscripción es la comunicación en un sentido amplio: se trata de transmitir un mensaje, un contenido, pero también de crear un vínculo entre el texto (como signo) y la sociedad. Como lo dice la epigrafista: "Se ve antes que se lee" . Por eso se pueden encontrar inscripciones colocadas en un sitio inalcanzable a la vista, indescifrable porque lo que cuenta es la conexión simbólica, el signo exterior de munificencia capaz de surtir efecto en los súbditos, los embajadores, los enemigos como lo recuerda también Elisa Ruiz García a propósito del poder de la escritura en general ${ }^{10}$.

Así, se puede pensar que tanto en el ámbito musulmán como cristiano, la inscripción, labrada con tanto arte, funciona más como un signo que como un discurso; un signo cuyo simbolismo remite a algo conocido por el receptor sin que éste entienda el significado exacto. Un signo cargado de simbolismo por la continuidad que existe entre las cortes y que tiene un impacto en el receptor. Cécile Treffort también muestra que los préstamos pueden expresar la voluntad de remitir a una cultura compartida y que el empleo de fórmulas estereotipadas puede resultar de una elección voluntaria: la de manifestar la coherencia o la unidad del grupo que las utiliza ${ }^{11}$. ¿Podría entonces ocurrir lo mismo con las inscripciones árabes en la Castilla cristiana? Los destinatarios de la escritura de aparato, a pesar de que ésta fuera en árabe, probablemente estaban familiarizados con este lenguaje simbólico que remitía a signos conocidos ya que desde el siglo XII las inscripciones están presentes en monumentos cristianos. Se trataría entonces de un signo de poder bien establecido que provoca la admiración y el respecto.

Michel Pastoureau ha recalcado la paradoja de la escritura circular: que es muy difícil de comprender mientras que contiene un mensaje destinado a ser entendido ${ }^{12}$. Esta paradoja es intrínseca a la epigrafía, tanto en un entorno musulmán como cristiano. Pero el impacto que puede tener la inscripción en la perspectiva de la propaganda no sólo reside en la lectura y desciframiento del texto; el impacto trasciende el contenido del mensaje. Así coincidimos con lo que dice Michel Pastoureau sobre el valor de la inscripción más afectivo y sacralizador que informativo o referencial ${ }^{13}$.

Uno de los efectos de la arquitectura palaciega es el de impresionar o intimidar al visitante, enfatizando la figura del soberano y el espacio que le corresponde. En este sentido, las inscripciones desempeñan también un papel simplemente por su ubicación, su tamaño o incluso su apariencia compleja.

$\mathrm{Si}$, como acabamos de ver, las inscripciones se deben considerar como un signo de poder establecido para el "público meta" tampoco hay que menospreciar el mensaje o

9 C. TREFFORT, Paroles inscrites. À la découverte des sources épigraphiques latines du Moyen Âge, Rosny-sous-Bois, 2008, p. 18.

10 E. RUIZ GARCÍA, "El poder de la escritura y la escritura del poder", J. M. NIETO SORIA (ed.), Orígenes de la monarquía hispánica. Propaganda y legitimación (CA. 1400-1520), Madrid, 1999, pp. 275313.

11 C. TREFFORT, op. cit. 2008, p. 27.

12 M. PASTOUREAU, "Un texte-image : l'écriture circulaire", Couleurs, images, symboles. Études d'histoire et d'anthropologie, Paris, 1989, p. 131.

13 Ibid., p. 137. 
el contenido discursivo. Consideramos que existen más bien varios niveles de lectura y que las inscripciones también transmiten una concepción de la realeza mediante el discurso.

\section{Un discurso ideológico: un Rey hecho por Dios, un Rey omnipresente y omni- potente}

La arquitectura refleja de manera tangible la potencia y la magnificencia del soberano mediante proezas técnicas y simbologías artísticas. Es, entonces, una demostración de fuerza, pero a su vez informa sobre la ideología del que encargó toda esta representación simbólica. José Manuel Nieto Soria subraya el vínculo que existe entre las formas de representación simbólica y la ideología:

"La principal forma de manifestación de una ideología política se produce a través de las representaciones del poder, constituyéndose por ello en objetivos esenciales de análisis, pudiéndolas considerar como los elementos descriptivos esenciales de los fenómenos ideológicos"14.

Así, por su doble naturaleza, arquitectónica y discursiva, las inscripciones permiten reflejar esta ideología de una realeza fuerte legitimada por Dios.

Aunque pueda parecer problemático que encontremos un léxico extraído del corpus sagrado islámico para pedir la bendición y el auxilio divino para un rey encargado de llevar a cabo el ideal de la reconquista, no creemos que haya una laicización del contenido. En el Alcázar de Sevilla, la omnipotencia de Dios aparece en muchas inscripciones recordando que Él es quien otorga su legitimidad al soberano: "al-'izza li-llah, al-baqa li-llah, al-mulk li-llah, al-qudra li-llah" (Gloria a Dios, Dios es eterno, Dios es el soberano, el poder pertenece a Dios). Mediante estas fórmulas doxológicas se reconoce la supremacía del poder divino al que el soberano está subordinado. Todas las inscripciones parecen adaptarse sin problema a un entorno cristiano y explotan la convergencia parcial entre el islam y el cristianismo: Dios hace reyes.

Probablemente el monarca debió de elegir inscripciones que no entrasen en contradicción con la fe católica. Esto mostraría que hubo realmente una intención por parte del monarca ${ }^{15}$. Además, hoy en día, la mayoría de los historiadores del arte coinciden en que no es la mano de obra la que determina la orientación artística sino que se trata de una libre elección por parte de los promotores ${ }^{16}$. Es entonces poco probable que el

14 J.M. NIETO SORIA, "Ideología y centralización política en la crisis bajomedieval: vías de aproximación y dificultades interpretativas", Historia a debate, C. BARROS (ed.), Santiago de Compostela, 1995, p. 153.

15 Este pragmatismo sería una ilustración del concepto de selección del que habla Thomas Glick: la cultura receptora no acepta todo lo que ofrece la cultura donadora, T. GLICK y O. PI-SUNYER, “Acculturation as an Explanatory Concept in Spanish History”, Comparative Studies in Society and History, 11 (1969), pp. 136154, especialmente p. 152.

16 A.J. MORALES MARTÍNEZ, "Los inicios de la arquitectura mudéjar en Sevilla.”, Metropolis Totius Hispaniae. 750 aniversario de la incorporación de Sevilla a la Corona Castellana, Sevilla, 1998, pp. 91-106, especialmente p. 102. 
rey dejara a sus artesanos escribir una inscripción sin haberla validado. Por lo menos debió exigir que no hubiera inscripciones en contradicción con la fe cristiana.

A través de muchas inscripciones, el rey afirma la legitimidad de su poder reconociendo la superioridad divina y amparándose bajo la protección de Dios. Esta idea aparece, por ejemplo, en la frase recurrente escrita en cursiva: "Ya thaqati ya amali anta al-raya anta al-wali ijtam bi-l-jayr 'amali” (Oh confianza mía, o esperanza mía, tú eres mi esperanza: tú eres mi protector, sella con la bondad mis obras) ${ }^{17}$. Además, esta oración dirigida a Dios, rodea la frase de elogio al sultán don Pedro escrita en cúfico, en casi todos los zócalos del palacio: "'izz li-mawlana al-sultan don bidru ayyadahu Allah" (Gloria a nuestro señor el sultán Don Pedro ayúdele Dios). La repetición de esta inscripción que contiene su título y su nombre, "al-sultan dun bidru", vuelve al soberano omnipresente. Esta omnipresencia del nombre del rey casi desemboca en una "transubstanciación del espacio en cuerpo monárquico" por retomar la expresión de Louis Marin ${ }^{18}$.

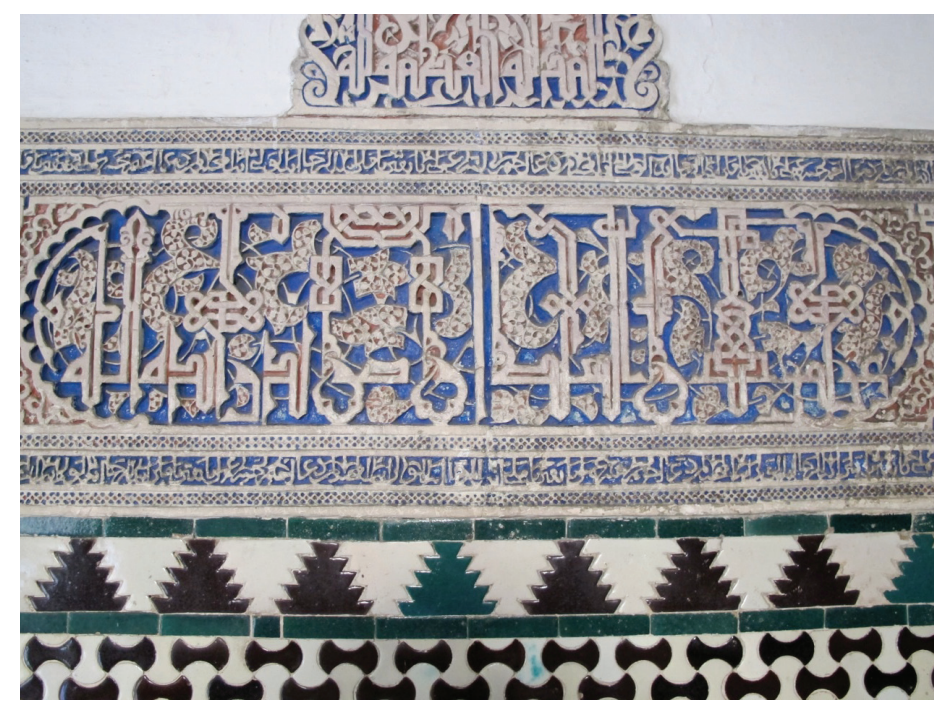

Fig. 1. Frase de elogio a Pedro I: "Gloria a nuestro señor el sultán Don Pedro ayúdele Dios".

Este valor performativo de la palabra se encuentra también en la repetición de oraciones jaculatorias que contribuyen a sacralizar el espacio del soberano "Al-gibta

17 R. AMADOR DE LOS RÍOS, op.cit., 1998, p. 135. Como muchas otras inscripciones del Alcázar, ésta aparece también en la Alhambra, por ejemplo en las tacas de entrada a las alcobas del Patio de Arrayanes. Pero a diferencia del palacio del rey cristiano, en la inscripción de la Alhambra se menciona además al profeta: "Por el profeta enviado, pon buen sello a lo que hago", ver J.M. PUERTA VÍLCHEZ, Leer la Alhambra. Guía visual del monumento a través de sus inscripciones, Granada, 2010, p. 82.

18 A. MADELEINE-PERDRILLAT (éd.), Louis Marin: le pouvoir dans ses représentations, Paris, 2008, p. 25: "il faut analyser le palais du Roi, comme le dispositif architectural d'appropriation de l'espace géographique urbain par le corps du Roi, la transsubstantiation de l'espace en corps monarchique." 
al-muttasila, al ni'ma al-shamila, al baraka al kamila" (La prosperidad continua, la gracia plena, la bendición completa); "al-yumn wa-l-iqbal wa-bulug al-amal" (La felicidad, la prosperidad y la consecución de los deseos). Mediante la repetición y el poder evocador de estos términos, las oraciones tienden a materializarse y a ser eficientes. El ritmo y la estructura de estas oraciones jaculatorias, que se encuentran también en la Alhambra, llevaron a Puerta Vílchez a atribuir a la epigrafía de este monumento un aspecto mántrico ${ }^{19}$. Los mantras son fórmulas sagradas que intentan alcanzar mediante la repetición, una especie de beatitud gracias al poder mágicoreligioso de la palabra o de la sílaba ${ }^{20}$.

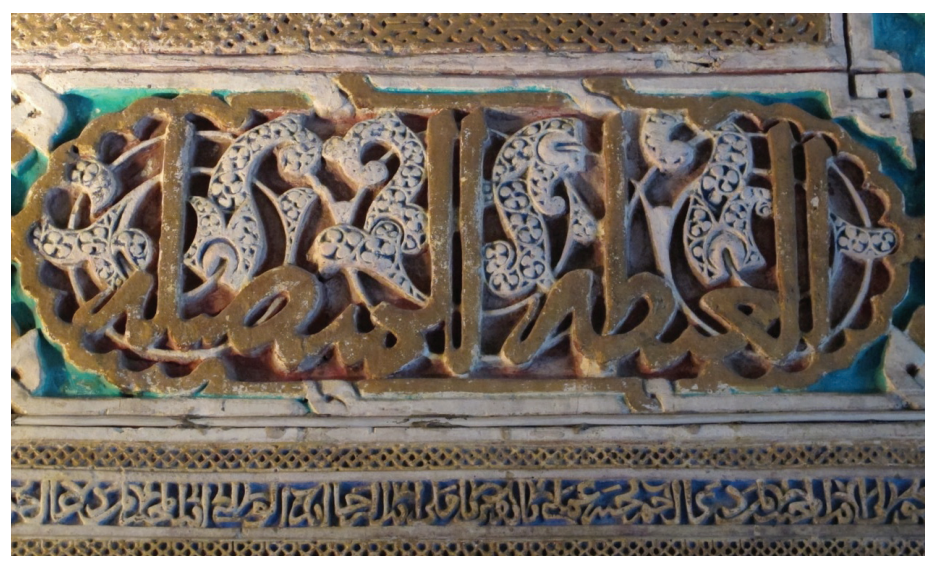

Fig. 2. Oración jaculatoria: "La properidad continua".

¿Se trata de transmitir una ideología, de convencer de que el palacio real es un espacio sagrado, una especie de intermediario entre el mundo terrenal y el celestial o simplemente se procura reflejar una concepción mística del poder ? Según Paul Veyne, habría que distinguir entre la información dada al otro y la expresión de sí mismo. El historiador, especialista de la Antiguëdad, considera que las imágenes políticas no son propaganda sino simple expresión de la legitimidad ${ }^{21}$.

Además, el discurso epigráfico no sólo expresa un contenido ideológico, que sería el de exaltar el poder casi absoluto del monarca, sino que la propia actividad discursi-

19 El profesor Puerta Vílchez retoma aquí una expresión de Emilio de Santiago, J.M. PUERTA VÍLCHEZ, op.cit., 2010, p. 102.

20 Esta promesa de un tiempo o estado beatífico corre en paralelo a la divisa del Duque de Berry en Francia "le temps venra", "el tiempo llegará". Agradezco a Alexandra Beauchamps el haberme comunicado esta referencia. Esta divisa adorna los palacios del duque, sobre todo el castillo de Mehun-sur-Yèvre, cerca de Bourges. A. BEN AMARA, et alii "Carreaux glaçurés provenant d'un château du Duc de Berry (Mehunsur-Yèvre, fin XIVe siècle): recherche d'indices techniques”, ArchéoSciences [En ligne], 29 | 2005, http:// archeosciences.revues.org/441.

21 P. VEYNE, "Propagande expression roi, image idole oracle", L'Homme, 30, 114 (1990), pp. 7-26. 
va es ideología ${ }^{22}$ en el sentido en que elegir el árabe o hacer convivir varios idiomas puede reflejar una voluntad hegemónica de apropiarse del Otro o presentarse como el monarca que domina todos los reinos de la Península.

\section{Actividad discursiva e ideología}

Hablamos de la continuidad entre las cortes castellana y granadina, pero si esta continuidad implica cierta emulación también conlleva una gran parte de rivalidad. Pedro I recurre a la titulatura de los sultanes granadinos en la fórmula de alabanza que adorna los muros del Alcázar. Esta fórmula es la misma que aquélla que rinde homenaje a Yusuf I y Muhammad V, los sultanes de Granada ${ }^{23}$ : “'izz li-mawlana al-sultan dun bidru ayyadahu Allah" (Gloria a nuestro señor el sultán Don Pedro, que Dios le ayude).

A primera vista, parece tratarse de un uso estereotipado, mecánico, lo que también puede ser revelador de un dato importante: el simple hecho de que Pedro I siga esta tradición muestra que estamos frente a una cultura cortesana común. Pero es más, este uso no está desprovisto de significación: no creemos que la presencia de esta inscripción resulte de una copia inocente, ni que se trate de un mero fenómeno de moda. En la mayoría de la inscripciones que remiten al rey, encontramos la palabra sultan excepto en la sala que corresponde a la antigua capilla, donde el término malik lo sustituye en tres ocasiones. Malik sería la mejor traducción para 'rey': “'izz li-mawlana al-malik dun bidru" "Gloria a nuestro señor el rey Pedro". Según el arabista Makram Abbes, que recurre al tratado sobre las divergencias linguísticas entre sinónimos de Al-'Askari, entre estos dos términos no hay una diferencia de naturaleza, sino más bien una diferencia de grado. Sultan sería de índole más pragmática que malik. Es lo que considera también el arabista Rafael Valencia: "sultan es el que ejerce el poder de manera práctica, mientras que malik es el detentor de la soberanía" ${ }^{24}$.

Hay que mencionar que la inscripción con el título malik es una innovación tanto en la epigrafía islámica como en la mudéjar, lo que muestra hasta qué punto el rey cristiano se apoderó de la epigrafía honorífica árabe. Sin embargo es la palabra sultan la que se arbora sin cesar y de manera muy visible en las paredes de todo el palacio (en cúfico y en nasji). Esta elección, seguramente voluntaria, podría interpretarse como una reivindicación política sobre todo el territorio de la Península y más precisamente sobre el reino de Granada. Además, sabemos que en la documentación castellana, Muhammad V es nombrado rey de Granada y no sultán.

22 E. RUIZ GARCÍA: "El propio medio transmitía ciertos valores ideológicos al margen de los mensajes expresados", op. cit., 1999, p. 290.

23 En la Alhambra son muy numerosas las inscripciones " izz li-mawlana al-sultan Abi l-Hayyay" (Yusuf I) y "'izz li-mawlana al-sultan Abi 'Abd Allah" (Muhammad V), cf. J.M. PUERTA VÍLCHEZ, op. cit., 2010, p. 57 y p. 129 .

24 R. VALENCIA, "Las inscripciones árabes en el arte mudéjar”, G. BORRÁS GUALIS (ed.), Mudéjar. El legado andalusí en la cultura española, catálogo de la exposición, Zaragoza, 2010, p. 297. 


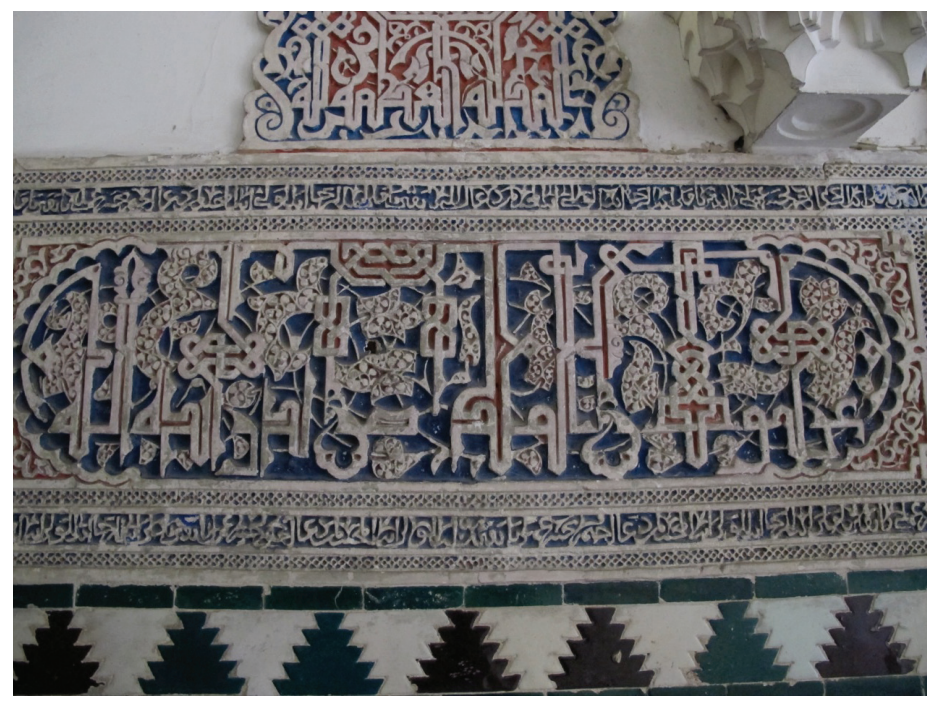

Fig. 3. Frase de elogio a Pedro I: "Gloria a nuestro señor el rey Don Pedro ayúdele Dios".

Así, esta re-contextualización de la titulación del monarca, lejos de corresponder a una pérdida de sentido o a una mera copia, sería el resultado de una voluntad política que tendría aún más significación. Al erigirse en sultán, Pedro I expresa su voluntad de afirmarse frente a sus enemigos o aliados, pero también quizás de presentarse como heredero de una tradición. Reanuda así la tradición de algunos de sus predecesores, Alfonso VI o Alfonso X, que solían presentarse como reyes de las tres religiones. Esta voluntad de apropiarse del Otro o de estampar su sello aparece también en los escudos de la monarquía castellana que irrumpen en la caligrafía árabe, así como en el hecho de retomar el lema nazarí "wa-la galiba illà-llah" como un tema propagandístico castellano.

Esta posible voluntad hegemónica de presentarse como el monarca que impone su autoridad en las tres religiones, se materializa también a través de la convivencia de lenguas en las inscripciones del Alcázar. Al igual que en la tumba de Fernando III o en la iglesia San Román de Toledo, las inscripciones árabes conviven con el latín y el romance. En las dos inscripciones fundacionales del Alcázar, se alaban los méritos del monarca constructor en dos idiomas y se alude a la fecha de la construcción según dos calendarios. La primera que aparece al visitante es la inscripción gótica de la fachada de la Montería escrita en romance:

"El muy alto et muy noble et muy poderoso et muy conqueridor don Pedro por la gracia de Dios rey de Castilla et de León, mandó fazer estos alcázares et estos palacios et estas portadas que fue hecho en la era de mill et quatro cientos y dos años"25.

25 Como Alfredo J. Morales ha indicado, esta fecha de 1402 corresponde a la era llamada "española" o "Era del César" que empieza en el año 38 antes de J.C. Equivale, pues, al año 1364 de la era cristiana. A.J. 
Esta inscripción rodea, además, el lema nazarí escrito en caracteres cúficos geométricos o rubai, en azulejos azules y blancos, machihembrados, que hacen posible una lectura de arriba hacia abajo o de derecha a izquierda ${ }^{26}$.

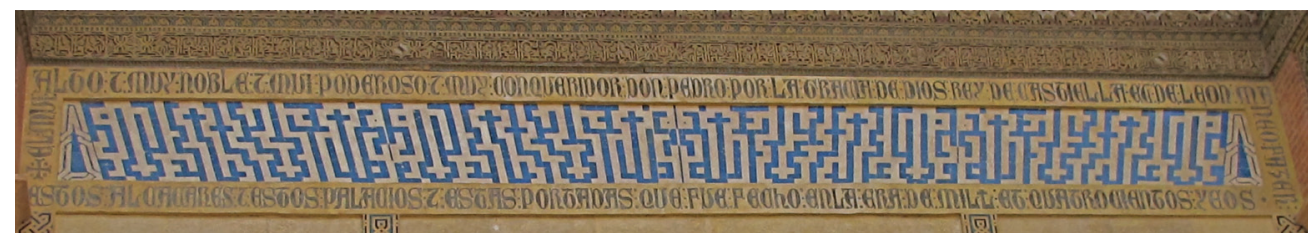

Fig. 4. Detalle de la fachada de la Montería.

La otra inscripción fundacional, en árabe, que aparece en las puertas del Salón de la Media Naranja, da la fecha en los dos calendarios:

[...] 'bi-tarij alf wa-arba' maya wa-arba' sinin li-tarij al-safar wa-wafiq min tarij al- 'arab sana saba'wa-sitin wa-saba' maya kamul al-bury bi-hamd Allah".

[...] "En la fecha de mil cuatrocientos cuatro años de la era hispánica, que se corresponde, en el calendario de los árabes, al año setecientos sesenta y siete, se terminó la construcción de esta fortaleza con la gracia de Dios"27.

Es interesante notar que, contrariamente a los edificios islámicos, no se alude a la Hégira para dar la fecha de construcción sino que se refiere al "calendario de los árabes" 28 . Es bastante frecuente anunciar la fecha según los calendarios de las tres religiones en los documentos castellanos ; es el caso por ejemplo de la crónica de Ayala que recurre a los tres calendarios para dar la fecha al principio de cada año ${ }^{29}$.

En definitiva, la epigrafía de los palacios de Pedro I demuestra la continuidad que existe entre las cortes árabes y las cortes castellanas ya que la inscripción puede considerarse como un signo de poder estereotipado, capaz de surtir efecto en el destinatario musulmán o cristiano. Aunque este signo encierra un verdadero discurso, una ideología de la realeza, el efecto que pueda provocar trasciende su significado por el valor casi mágico de la palabra que sacraliza el espacio y por la propria iniciativa de recurrir al árabe, que refleja un deseo de poder hegemónico en el que se mezclan la admiración y el deseo de absorber al Otro.

\footnotetext{
MORALES y J.C. HERNÁNDEZ NÚÑEZ, El Real Alcázar de Sevilla, Londres, 1999, p. 45.

26 Para más detalles sobre esta inscripción, vid. R. VALENCIA, op.cit. 2010, p. 301.

27 P. CANO ÁVILA y A.T. MOHAMED ESSAWI, op. cit. 2004, p. 56.

28 Agradezco al profesor Alberto Montaner el haberme indicado este detalle.

29 P. LÓPEZ DE AYALA, Crónica del rey Don Pedro y del rey Don Enrique, su hermano, hijos del rey don Alfonso Onceno, G. ORDUÑA (ed.), Buenos Aires 1994.
} 